\title{
Familial Aggregation of Cognitive Biases for Children with Anxiety Disorders
}

\author{
Jasmijn M. de Lijster ${ }^{1}$. Elisabeth M. W. J. Utens ${ }^{1,2,3}$. Gwendolyn C. Dieleman ${ }^{1} \cdot$ Tamsin M. Alexander $^{4}$. \\ Manon H. J. Hillegers ${ }^{1}$. Jeroen S. Legerstee ${ }^{1}$
}

Published online: 19 July 2019

(c) The Author(s) 2019

\begin{abstract}
Previous studies described a relation between anxiety-related cognitive biases in normally developing children and parents. The current study examined the familial aggregation of cognitive biases in children with anxiety disorders $(N=55)$ and their parents, with possible moderators and mediators as mechanisms underlying this aggregation. Cognitive biases for children were measured by the dot-probe task for attention bias and by ambiguous stories for interpretation bias. Mothers' $(n=50)$ and fathers' $(n=30)$ lifetime mood and anxiety disorders were assessed, along with their attention bias (dot-probe task) and self-reported rearing styles. Results showed an association between maternal attention bias and interpretation bias of children $(r=0.31, p=0.032)$. However, this association was neither moderated by maternal lifetime mood or anxiety disorders nor mediated by maternal rearing styles. The familial aggregation of maternal attention bias and children's interpretation bias is presumably influenced by other factors than maternal mood or anxiety disorders or rearing styles.
\end{abstract}

Keywords Cognitive biases · Childhood anxiety disorders $\cdot$ Mediating effect $\cdot$ Moderating effect $\cdot$ Familial aggregation · Parenting

Accumulating evidence shows that children with anxiety disorders have cognitive biases that are involved in both the development, maintenance, and treatment response of anxiety (Dodd et al. 2012; Dudeney et al. 2015; Pérez-Edgar et al. 2011; Waters and Craske 2016; Legerstee et al. 2009; Waters et al. 2012). In particular, information processing in children with anxiety disorders is biased towards threatrelated information in the environment (Lonigan et al. 2004). Several cognitive biases have been related to anxiety

Jeroen S. Legerstee

j.s.legerstee@erasmusmc.nl

1 Department of Child and Adolescent Psychiatry/Psychology, Erasmus MC-Sophia Children's Hospital, Erasmus University Medical Center, P.O. Box 2060, Wytemaweg 80, 3000 CB Rotterdam, The Netherlands

2 Research Institute of Child Development and Education, University of Amsterdam, Amsterdam, The Netherlands

3 Academic Center for Child Psychiatry the Bascule/Department of Child and Adolescent Psychiatry, Academic Medical Center, Amsterdam, The Netherlands

4 Lucertis Child and Adolescent Psychiatry, Parnassia Psychiatric Institute, Rotterdam, The Netherlands disorders that occur at different stages of information processing, such as attentional biases, interpretation biases, and confirmation biases. As these cognitive biases have a central role in childhood anxiety disorders (Dudeney et al. 2015; Pine et al. 2009), studies have also examined the familial aggregation of anxiety-related biases.

Several studies have focused on the familial aggregation or co-occurrence of cognitive biases in parents and children within community samples and found associations between mothers' and children's anticipation of distress (Creswell et al. 2006, 2011), threat interpretations (Creswell et al. 2005; Creswell and O'Connor 2006) and information search bias (Remmerswaal et al. 2016). Moreover, Lester et al. (2009) showed that parents exhibit the same interpretation biases in threatening situations that involved themselves as compared to threatening situations that involved their children. Thus, parents' threat interpretations within their own environment are likely to be related to threat anticipated for their child. However, Gifford et al. (2008) showed in a clinical sample that threat interpretations made by anxietydisordered children and their mothers were not related, but mother's threat interpretation was related to anxiety reported by the child. The contradictory results between community 
and clinical studies highlight that other dyadic influences could be at play when relating information processing between parents and children within clinical samples.

Although previous studies have related cognitive biases in children to parents' cognitive biases, the mechanism through which parental biases influence children's biases is not fully understood. Parents may contribute to the transmission of cognitive biases through several mechanisms, such as parental modeling, parental reinforcement of anxious or avoidant behavior, and information transfer (Chorpita and Barlow 1998; Hadwin et al. 2006; Fisak and Grills-Taquechel 2007; Ooi et al. 2016). For example, parental psychopathology has been related to both symptoms of anxiety and cognitive biases in children (Kujawa et al. 2011; Muris et al. 2010; Montagner et al. 2016). In the study of Waters et al. (2015) attention bias in children was related to the attention bias of mothers with a lifetime mood or anxiety disorder only. This suggests a moderating role for parental psychopathology, assuming that the relation between biases in children and parents is influenced by whether anxiety in the family is clinically expressed (Legerstee and Utens 2018). In addition, parents' cognitive biases may exert influence on their children by parental rearing practices (Finegood et al. 2017). As parenting behaviors have also been associated with anxietyrelated cognitive biases in children (Gulley et al. 2014; Gibb et al. 2011), parenting could operate as a mediating variable in this familial aggregation.

Previous studies into the relation between parental and child cognitive biases have mostly been carried out in community samples (Creswell et al. 2005, 2006, 2011; Creswell and O'Connor 2006; Remmerswaal et al. 2016). Although these studies provide valuable insights into the role parents may play in the development of cognitive biases, the familial aggregation of cognitive biases in clinical samples can contribute to our understanding of the intergenerational transmission of anxiety disorders. Even though fathers have been shown to play an important role in childhood anxiety (Bögels and Phares 2008), fathers have been rarely involved when studying parental and child cognitive biases. The current study aims to fill this gap in the literature of familial aggregation of cognitive biases in clinical samples by examining the aggregation of attention and interpretation biases in children with anxiety disorders and both mothers' and fathers' attention bias. We hypothesized that cognitive biases between children and their parents would be related, without specific expectations for differences between mothers and fathers. The second aim of this study was to examine the influence of both maternal and paternal psychopathology and rearing styles as respectively, moderators and mediators in the familial aggregation of these cognitive biases. Based on the literature, we hypothesized that the familial aggregation of cognitive biases would be especially apparent for parents with past or current psychopathology. Also, we hypothesized that this aggregation would be mediated by parental rearing styles that have previously been associated with anxiety-related cognitive biases in children. Whereas in the literature also the term familial transfer or transmission is used, we here refer to aggregation, considering the bottom-up approach of our study.

\section{Methods}

\section{Participants}

The sample consisted of 55 children $(M$ age $=11.15$, $S D=2.27$, range $=8.04-16.91)$, of whom their mothers and fathers were also asked to participate. In total, 50 mothers (91\% of all mothers, $n=55)$ and 30 fathers (61\% of all fathers, $n=49$ ) agreed to participate themselves. Descriptive characteristics of children and participating parents are displayed subsequently in Tables 1 and 2. Children with participating parents did not differ on severity score of primary anxiety diagnosis compared to children with nonparticipating parents $(t(53)=1.02, p=0.312)$. Participating parents did not differ on demographic characteristics from non-participating parents $(t<1.78, p \mathrm{~s}>0.081)$.

Eligible for participation were children consecutively referred to the outpatient clinic of the Erasmus Medical Center, Sophia's Children's Hospital or the Lucertis Center for Child and Adolescent Psychiatry in the Rotterdam area, The Netherlands, between September 2013 and July 2016. This study is part of a larger research project to investigate the role of cognitive biases in the treatment of childhood anxiety disorders by examining the effectiveness of attention bias modification (ABM) in combination with Cognitive Behavioral Therapy (CBT) (de Lijster et al. 2019). This

Table 1 Descriptive characteristics for children $(\mathrm{N}=55)$

\begin{tabular}{ll}
\hline & Children $(N=55)$ \\
\hline Age $(M, S D)$ & $11.15(2.27)$ \\
Gender ratio (M:F) & $27: 28$ \\
Ethnicity (n, \%) & \\
Dutch & $34(61.8)$ \\
Non-Dutch & $4(7.3)$ \\
Missing & $17(30.9)$ \\
ADIS-C/P EBC $\geq 4(n, \%)$ & \\
Separation anxiety disorder & $15(27.3)$ \\
Social phobia & $19(34.5)$ \\
Specific phobia & $25(45.5)$ \\
Generalized anxiety disorder & $29(52.7)$ \\
SES $(M, S D)$ & $0.22(1.29)$ \\
IQ $(M, S D)$ & $104.45(12.42)$ \\
\hline
\end{tabular}

${ }^{\text {a }}$ Socioeconomic represents a continuous status z-score 
Table 2 Descriptive characteristics for mothers $(n=50)$ and fathers $(\mathrm{n}=30)$

\begin{tabular}{|c|c|c|}
\hline & Mothers $(n=50)$ & Fathers $(n=30)$ \\
\hline \multicolumn{3}{|c|}{ Lifetime child mood or anxiety disorder $(n, \%)$} \\
\hline No & $29(58)$ & $23(76.7)$ \\
\hline Yes & $21(42)$ & $7(23.3)$ \\
\hline Panic disorder & $1(2)$ & - \\
\hline Agoraphobia & - & - \\
\hline Social phobia & $1(2)$ & - \\
\hline Specific phobia & $12(24)$ & $6(20)$ \\
\hline Generalized anxiety disorder & - & - \\
\hline Obsessive compulsive disorder & - & - \\
\hline Posttraumatic stress disorder & $2(4)$ & - \\
\hline Dysthymic disorder & $1(2)$ & - \\
\hline Major depressive disorder & $14(28)$ & $3(10)$ \\
\hline \multicolumn{3}{|l|}{ EMBU-P $(M, S D)$} \\
\hline Emotional Warmth & $67.72(6.05)$ & $65.79(7.04)$ \\
\hline Rejection & $24.12(3.23)$ & $24.24(3.58)$ \\
\hline Over protection & $17.48(3.86)$ & $15.79(2.60)$ \\
\hline Age $(M, S D)$ & $43.06(4.36)$ & $45.01(6.03)$ \\
\hline
\end{tabular}

study was approved by the Medical Ethics Committee of the Erasmus Medical Center in Rotterdam, The Netherlands (MEC-2013-375) and the randomized controlled trial was registered with ClinicalTrials.gov, number NCT03764644.

Inclusion criteria were based on children's eligibility for CBT: age between 8 and 16 years along with a primary diagnosis of separation anxiety disorder (SAD), social phobia (SOP), specific phobia (SP), or generalized anxiety disorder (GAD), according to the Anxiety Disorders Interview Schedule for children and parents (ADIS-C). Exclusion criteria were a total IQ of 85 or less, poor command of the Dutch language, serious physical disease, psychosis, substance abuse, autism spectrum disorders, obsessive-compulsive disorder (OCD), posttraumatic stress disorder (PTSD), acute stress disorder, panic disorder (PD), agoraphobia (AGO), major depressive disorder (MDD), and current pharmacological anxiety treatment or psychological treatment in the past 6 months. Children who fulfilled the study criteria but declined to participate $(n=11)$ did not differ regarding gender, age, SES, or anxiety disorder severity compared to eligible children who participated $(t<1.64, p s>0.105)$.

\section{Measures}

\section{Demographics}

IQ was measured as full scale IQ by the Weschler Intelligence Scale for Children-III (WISC-III) and part of the regular clinical assessment. When IQ was not part of clinical assessment $(n=6)$, tasks verbal fluency and block patterns of the WISC-III were used for inclusion into the study. Socioeconomic status (SES) was based on the residential area of the children and their families, for which SES status z-scores were derived based on the average household income, level of education, and employment rates of the area (Knol et al. 2012). Higher status z-scores indicate higher SES.

\section{Compositional Interview Diagnostic Schedule (CIDI) for Parental Psychopathology}

The CIDI 2.1 (WHO 1997) is a fully structured and computerized diagnostic interview and was used to assess parental lifetime and current anxiety and mood disorders according to criteria of the DSM-IV. Based on the CIDI 2.1, the following anxiety disorders were classified: namely SP, PA, AGP, SOP, GAD, OCD, and PTSD. In addition: MDD, depression NAO, dysthymia, bipolar disorder, and cyclothymic disorder were diagnosed as lifetime or current mood disorders. Master level students were trained for the assessment of the computerized CIDI. As the computerized CIDI provides classifications, the interview can be administered with minimal training as clinical judgment is not required (Cooper et al. 1998). The reliability of the CIDI 2.1 has been demonstrated to be excellent, and the validity has been demonstrated to be adequate (Andrews and Peters 1998; Wittchen 1994). Parental psychopathology was defined as the presence or absence of a current or lifetime anxiety or mood disorder. Lifetime disorders which duration ended before the child was born, were considered as no parental psychopathology for analyses.

\section{Egna Minnen Beträffande Uppfostran, Parent Report (EMBU-P)}

The EMBU-P (Swedish acronym for My Memories of Upbringing) assessed parental rearing styles from the parents' perspective. Conceptually, the parent report version is very similar to the child report questionnaire EMBU-C (Markus et al. 2003) and the items reflect parents' current thoughts on their own parenting practices and experiences of parenting behavior. For the current study, the subscales emotional warmth (19 items), rejection (18 items), and overprotection (10 items) were assessed on a 4-point scale ( $1=$ no, never, $2=$ yes, sometimes, $3=$ yes, often, $4=$ yes, most of the time). In this study, subscale internal consistency for mothers was $0.85,0.73$, and 0.74 and for fathers 0.89 , $0.76,0.57$, which is generally in line with the psychometric properties reported for the EMBU-C (Markus et al. 2003). For the overprotection scale, the item "If your child has a secret, you want to know them" was removed due to insufficient item-total correlations. 


\section{Attention Bias Children and Parents}

Attention bias in children and parents was measured with the dot-probe detection task. This task was programmed using E-prime v2.0 (Psychology Software Tools, Inc.) and presented on a Fujitsu Lifebook computer in a quiet room with minimal visual and auditory distractions. In this task, a cross appeared in the middle of the screen for $500 \mathrm{~ms}$ followed by two stimuli shown simultaneously (left and right) for $500 \mathrm{~ms}$ for each trial. Stimuli and total number of trials were the same for parents and children and followed by a probe in the spatial location previously occupied by one of the pictures. Probes consisted of two dots that were either placed next to each other or above each other and were shown until one of the corresponding labeled keys were pressed. Participants were instructed to respond as accurately and quickly as possible. Because of a software defect, attention bias could not be assessed for one mother. For two fathers, attention bias was missing because they could not physically attend the research assessment.

Ten practice trials with neutral stimuli were performed which allowed a maximum of four errors. Practice trials were repeated if children made more than four errors. After the practice trials, four blocks consisting of 40 trials each (180 trials in total) were performed and participants were allowed to take short breaks in between. Picture pairs were either threatening-neutral (128 trials) or neutral-neutral (32 trials). For threatening-neutral pairs, probes occurred in half of the trials at the same spatial location as the threatening picture (congruent trials) and in half of the trials at the opposite location of the threatening picture (incongruent trials).

Because of the high rate of homotypic comorbidity of anxiety disorders (Wittchen et al. 2007), stimuli reflected all included anxiety disorders (SAD, SP, SOP, and GAD). For $\mathrm{SAD}$, pictures that showed either separation (threatening) or reuniting (neutral) scenarios of adults and children were used (In-Albon et al. 2009). Pictures of faces expressing anger or disgust (threatening) or neutral faces from a set of Japanese and Caucasian Facial Expressions of Emotions (JACFEE; Biehl et al. 1997; Matsumoto and Ekman 1988) were used to reflect SOP. For SP, pictures were selected from the International Affective Picture System (IAPS; Lang et al. 1997) of animals (e.g. a barking dog), blood, and threatening phenomena in nature, along with neutral pictures of objects or nature. Four additional pictures of a tunnel and elevator were taken to ensure full coverage of different phobias. The first three blocks comprised the SAD, SOP, and SP stimuli per participant in a randomized order. In the final block, threat-related and neutral words were selected to comprise GAD from the Dutch Affective Words List (Moors et al. 2013) because of the difficulty to visualize words like "dead" or "pain". Both the location of the probes, number of (in)congruent trials and type of stimuli (for the first three blocks) were counterbalanced across trials. In this study, we calculated the average attention bias for children, mothers, and fathers across anxiety disorder stimuli subtype.

Data preparation was conducted in line with previous studies with excluding Reaction Times (RTs) from trials with errors, if RTs were $<200 \mathrm{~ms},>1500 \mathrm{~ms}$, and when $>2.5 \mathrm{SD}$ above the participant's mean RT (Montagner et al. 2016; Shechner et al. 2014). The average amount of excluded trials was $15.2 \%$ for children, $5.9 \%$ for mothers, and $6.8 \%$ for fathers. In line with previous studies, attention bias scores were calculated by subtracting the average RT on congruent trials from the average RT on incongruent trials (Roy et al. 2008). Positive values represent greater attention towards threatening compared to neutral stimuli, whereas negative values reflect attention away from the threatening relative to neutral stimuli.

\section{Interpretation Bias Child}

We used ambiguous stories to measure children's interpretation bias (Muris et al. 2000). Nine audiotaped, hypothetical stories consisting of five sentences each were used, with three types of stories: separation anxiety stories (e.g. your parents go on holiday and you have to stay with your aunt), social anxiety stories (e.g. first day at a hockey training), and generalized anxiety stories (e.g. you have to make a very difficult test at school). After listening to the stories, the child was asked to tell the researcher how he or she thinks that the story will end. The researcher wrote what the child said verbatim. Two raters who were blind to the other collected measures judged whether the child interpreted the story as scary (1) or non-scary (0). An interrater reliability analysis using the Kappa statistic was performed to determine consistency among the two raters (McHugh, 2012). For the category separation anxiety the interrater reliability was Kappa $=0.73(p<0.001)$, for social anxiety $\kappa=0.83$ $(p<0.001)$ and for generalized anxiety $\kappa=0.71(p<0.001)$. For total interpretation bias score in statistical analyses, a total score (max. 9) was created by summing up the scores of all stories. Two children could not complete the interpretation bias task because of time concerns. In addition, a weighted total score was created when one score of the three story types was missing $(n=2)$.

\section{Procedure}

The ADIS-C was completed before participation in the study as part of the regular clinical assessment. After the clinical assessment was completed, parents and children were informed about the study verbally and with patient information letters in which the concept of attention bias was explained in layman's language. At the day of the research assessment, children and their parent(s) were invited to the 
outpatient clinic for which parents received a compensation of their travel costs but no participation fee. Informed consent was obtained from both parents and children aged 12 years and older and from parents regarding their own participation. After signing informed consent, both children and parents were given instructions about the dot-probe task. Participants were told they would see different images and their task was not to pay attention to the images but to respond to the appearing dots. Children first performed the dot-probe task and subsequently the interpretation bias task which was explained as listening to stories that were either "scary" or "non-scary" and it was their task to guess how each story would end. In the meanwhile, parents alternately completed the CIDI, dot-probe task and digital questionnaires in a separate room. No debriefing was given regarding the tasks.

\section{Statistical Analyses}

All analyses were performed with SPSS version 24 (IBM 2017). To describe the familial aggregation between parents' and children's attention biases, paired sample t-tests for attention bias were used. In addition, bivariate associations were computed with Pearson correlation coefficients between parents' attention bias and children's attention bias and interpretation bias. Follow-up moderation and mediation analyses were performed for significant associations between parents' attention bias and children's attention bias and interpretation bias. Models of moderation were analyzed separately for mothers and fathers in which parental psychopathology was hypothesized to moderate the familial aggregation of parental attention bias and children's cognitive biases. Models of mediation were analyzed separately for mothers and fathers with parental rearing styles as mediating variables. Formal moderation and mediation analyses were performed using the 'PROCESS' macro for SPSS, version 3.3 (http://www.afhayes.com/) with bias-corrected bootstrapping using 1000 replications for mediation analyses (Preacher and Hayes 2008). Because of the explorative character of the study, $\alpha=0.05$ was used for all statistical analyses without correcting for multiple testing.

\section{Results}

\section{Descriptive Analyses}

\section{Child and Parental Disorders}

Table 1 shows the descriptive and clinical characteristics of children and parents. Children most often had an ADIS-C severity rating of $\geq 4$ for GAD (52.7\%) and SP (45.5\%) and comorbidity was high $(49.1 \%)$. Table 2 shows that less than half of the mothers (42\%) fulfilled the criteria of a mood or anxiety disorder during the lifetime of the child and SP (24\%) and MDD (28\%) were the most common disorders. In total, seven fathers $(23.3 \%)$ fulfilled the criteria for a mood or anxiety disorder during the lifetime of their child. For fathers, SP and MDD were the only classified disorders (20\% and $10 \%$, respectively).

\section{Cognitive Biases for Children and Parents}

On average, the direction of the attention bias of anxiety-disordered children was towards threat $(M=11.31, S D=44.89)$ for which the one sample $t$ test of statistical difference from zero showed a trend towards significance $(t(54)=1.87$, $p=0.067, d=0.25)$. The direction of the attention bias of mothers was also towards positive $(M=4.45, S D=29.73)$ but not significant different from zero $(t(48)=1.05$, $p=0.300, d=0.15)$. Fathers attention bias was away from threat $(M=-7.76, S D=17.42)$, and significantly differed from zero $(t(27)=-2.36, p=0.026, d=0.45)$.

Paired samples t-tests indicated a statistical difference between the attention bias scores of children and fathers $(t$ $(27)=2.57, p=0.016, d=0.76)$, but not between children and mothers $(t(48)=1.32, p=0.192, d=0.36)$. Children's threatening interpretations ranged from zero to seven out of the nine stories $(M=1.82, S D=1.79)$. When relating demographic characteristics in relation to children's cognitive biases, no variable (gender, age, SES, IQ) was either related to attention bias or threat interpretation scores (all $r<0.23$, $p>0.116$ ). Also, parents' age and SES was not related to their attention bias scores (all $r<0.18, p>0.375$ ).

\section{Familial Aggregation of Cognitive Biases}

A correlation matrix is presented in Table 3 with the strength of the relations between parental and children's cognitive biases. Attention bias scores of mothers and fathers were not related to attention bias scores of children $(r=-0.23$, $p=0.109, r=-0.29, p=0.138$ ). For children's interpretation bias, a significant small positive correlation was found with

Table 3 Familial aggregation of cognitive biases for children and parents

\begin{tabular}{lllll}
\hline & $\begin{array}{l}\text { Maternal } \\
\text { attention bias }\end{array}$ & $\begin{array}{l}\text { Paternal atten- } \\
\text { tion bias }\end{array}$ & $\begin{array}{l}3 \\
\text { Child atten- } \\
\text { tion bias }\end{array}$ & $\begin{array}{l}4 \\
\text { Child inter- } \\
\text { pretation } \\
\text { bias }\end{array}$ \\
\hline 1 & 1 & - & - & - \\
2 & -0.10 & 1 & - & - \\
3 & -0.23 & -0.29 & 1 & - \\
4 & $0.31^{*}$ & -0.10 & -0.04 & 1 \\
\hline
\end{tabular}

$*$ p-value $<0.05$ 
maternal attention bias $(r=0.31, p=0.032)$. Thus, attention bias towards threat for mothers was associated with more threat interpretation biases in children. Fathers' attention bias score was not related to threat interpretations made by children $(r=-0.10, p=0.632)$.

\section{Effects of Parental Psychopathology and Rearing Styles}

Follow-up analyses were performed for the association between maternal attention bias and children's interpretation bias (Fig. 1a). The moderation effect of maternal psychopathology and the mediating effect of rearing styles were examined (as displayed in Fig. 1b-e).

\section{Moderation Effect of Maternal Psychopathology}

A moderation analysis was performed to assess whether the association between maternal attention bias and children's attention bias was influenced by maternal psychopathology. The moderation analysis showed no interaction between maternal attention bias and maternal psychopathology $(B=0.00, t(47)=0.19, p=0.852,95 \% \mathrm{CI}-0.03$; $0.04)$. Also, there were no main effects of maternal attention bias $(B=0.02, t(47)=1.99, p=0.053)$, or maternal

(a)

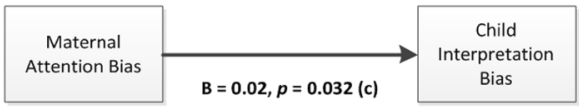

(b)

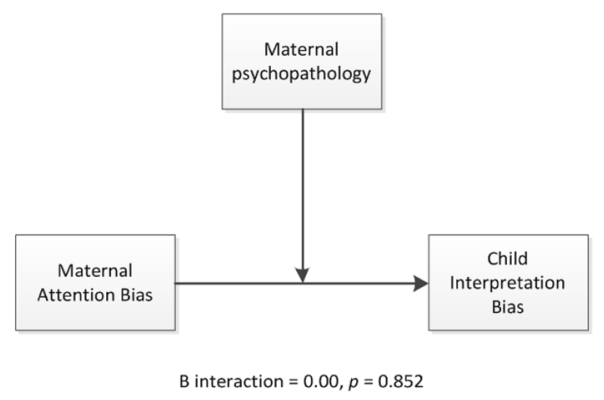

psychopathology $(B=0.42, t(47)=0.78, p=0.439)$ on children's interpretation bias score.

\section{Mediation Effect of Maternal Rearing Styles}

To assess whether rearing styles were mediators in the association between maternal attention bias and child interpretation bias, three mediation analyses were performed for maternal emotional warmth, maternal rejection, and maternal overprotection separately (as displayed in Fig. 1b-d).

The first mediation analysis for maternal emotional warmth showed that the direct effect (c' path) of maternal attention bias on child interpretation bias remained significant after controlling for maternal emotional warmth $(B=0.02, t(47)=2.24, p=0.030,95 \%$ CI $0.00 ; 0.04)$. The indirect $(\mathrm{a} * \mathrm{~b}$ path) effect through maternal emotional warmth was small and not significant $(B=0.00,95 \% \mathrm{CI}$ $-0.01 ; 0.00)$. This implies that the total effect (c' path) between maternal attention bias and child interpretation bias was not mediated by maternal emotional warmth.

In the second mediation analysis, adding maternal rejection to the model led to a non-significant direct effect (c' path) of maternal attention bias on child interpretation bias $(B=0.02, t(47)=1.92, p=0.061,95 \%$ CI $0.00 ; 0.04)$. The indirect ( $\mathrm{a} * \mathrm{~b}$ path) effect through maternal rejection was

(c)

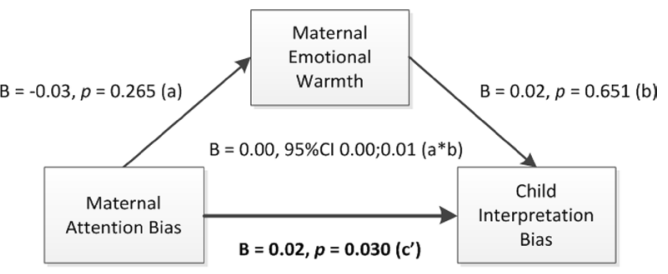

(d)

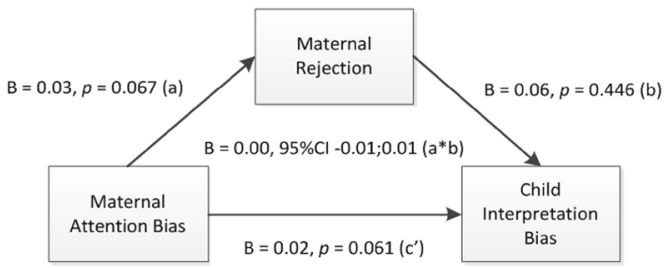

(e)

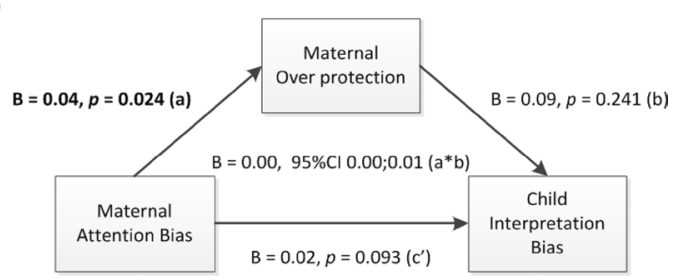

Fig. 1 Moderation (b) and mediation analyses (c-e) between maternal attention bias and child interpretation bias (a) 
small and not significant $(B=0.00,95 \% \mathrm{CI}-0.01 ; 0.01)$, indicating no mediating effect of maternal rejection.

For the third mediation analysis, maternal attention bias was significantly related to maternal over protection (a path), $B=0.04, t(47)=2.34, p=0.024,95 \%$ CI $0.01 ; 0.07$. The direct effect (c' path) of maternal attention bias on child interpretation bias was not significant after controlling for maternal over protection $(B=0.02, t(47)=1.72, p=0.093$, $95 \%$ CI $-0.00 ; 0.03)$. The indirect ( $\mathrm{a} * \mathrm{~b}$ path) effect through maternal over protection was small and not significant $(B=0.00,95 \% \mathrm{CI}-0.00 ; 0.01)$. Thus, the total effect (c' path) between maternal attention bias and child interpretation bias was not mediated by maternal over protection.

\section{Discussion}

The first aim of this study was to examine the familial aggregation of cognitive biases in children with anxiety disorders and their parents. Results showed that maternal attention bias was related to the interpretation bias of children. In contrast to our hypothesis, children's attention bias was not related to parental attention bias within this study's clinical sample. The second aim of this study was to examine the effect of parental psychopathology and rearing styles as respectively, moderators and mediators in the familial aggregation of cognitive biases. In contrast to our expectations, the association between maternal attention bias and children's interpretation bias was not significantly influenced by maternal psychopathology, neither were maternal rearing styles found to mediate this relation. The current study adds to previous community studies into cognitive biases in children and parents by demonstrating how these biases are interrelated when children are diagnosed with an anxiety disorder.

Although the effect was small, maternal attention bias towards threat was related to more threat interpretations made by children. There are several explanations for this familial aggregation from maternal attention bias to child interpretation bias. First, attention bias of mothers could affect their own information processing at a later stage than attention regulation, which correlates with their child's interpretation bias. However, as the previous study with a clinical sample by Gifford et al. (2008) found no relation between interpretation biases of mothers and children, so far this is not supported by the literature. Second, as attention bias operates at a subliminal level, another explanation could be that children observe their mother's verbal or behavioral response following their attention bias (Waters and Craske 2016). This explanation is in line with the indirect transmission of maternal attention biases to offspring proposed by Waters et al. (2015) via greater exposure to negative information by mothers. Third, maternal attention bias could be a response to children's interpretation bias. Previous studies in community and at-risk samples have shown a reciprocal relation between children's cognitive bias and maternal attention bias and expectations of their child's anxious cognitions (Creswell et al. 2006, 2011; Waters et al. 2018).

In contrast to our expectations, we found no association between parents' attention bias and children's attention bias. In the study by Waters et al. (2015), attention bias towards threat for children was associated with attention bias away from happy faces for mothers with lifetime emotional disorders. As we only measured attention bias towards threat, we could not test whether some mothers had an attention bias away from happy stimuli. A more recent study examined the prospective and concurrent relations between anxiety and attention bias of children and parents in a community sample. This study by Aktar et al. (2019) showed that instead of attention biases of parents being a predictor for children's attention bias at 7.5 years, parents' anxiety when children were 4.5 years old predicted children's attention bias over time. Because we used an experimental study design, we could not examine the developmental change of cognitive biases for children. It should be mentioned that in line with previous studies (for an overview, see Mogg et al. 2017), children in our study did not have a significant attention bias towards threat. In contrast to adults, the relative role of attention bias for children with anxiety seems to be minor (Abend et al. 2018).

The current study included both mothers and fathers and hence, we were able to contrast findings regarding paternal and maternal influences. Interestingly, children's direction of attention bias was different from the attention bias measured for their fathers. Although not significantly different from zero, children's direction of attention bias was towards threat (Puliafico and Kendall 2006). In contrast, fathers were found to have an attention bias away from threat. It has been suggested that when faced with threat, fathers are the first person children turn to as they search for clues how to interpret the situation (Bögels and Phares 2008; Kilic et al. 2003). In the presence of their fathers, for children with anxiety disorders, reassurance from fathers regarding threat may be no longer sufficient. This could explain why children are hypervigilant for threat as their fathers avoid threat-related cues. However, in the current study, attention bias between fathers and children was not related and cognitive biases in children could also be irrespective of their fathers' bias.

Although maternal self-reported overprotection was associated with an attention bias towards threat for mothers, we found no effect of maternal psychopathology or rearing styles in explaining the familial aggregation of cognitive biases in children and mothers. Several studies have shown the aggregation of anxiety disorders in families (Low et al. 2012; Connell and Goodman 2002). However, the familial aggregation of maternal attention bias and children's 
interpretation bias was not moderated by maternal psychopathology in the current study. Possibly, transmission of anxiety-related cognitive biases is stronger for specific anxiety disorders, which has previously been shown for PD in parents and negative interpretation of panic scenarios for children (Legerstee and Utens 2018). An alternative explanation for the lack of the moderating effect of maternal psychopathology could be that cognitive biases aggregate in families regardless of mothers' history of emotional disorders. In addition, the direct effect between maternal attention bias and children's interpretation bias disappeared when maternal rejection and overprotection were added to these models. This suggests that these parenting styles may not be distinctive constructs but instead overlap with cognitive biases in parents. Instead of parental psychopathology and overall parenting styles, other, more specific parental practices in threatening or stressful situations may influence the transmission of cognitive biases (Darling and Steinberg 1993). This is supported by two previous twin-studies showing that up to $70 \%$ of the variance in anxiety-related cognitive biases can be explained by the non-shared environment (Eley et al. 2008; Lau et al. 2012). More dysfunctional parent practices such as lack of consistency of expectations, restricted communication, and poor interpersonal relationship may play a role as the study by Blossom et al. (2013) found an association between child reported family dysfunction and children's threat bias.

A strength of the current study is that we examined the association of several parental characteristics with different cognitive biases in children with anxiety disorders. Previous studies examined this association in community samples, although cognitive biases in children with anxiety disorders are different from normally developing children (Waters et al. 2010). Also, by examining both attentional and interpretation bias in children, we could further isolate familial aggregation of these cognitive biases with parental characteristics. In addition, fathers have been rarely involved in previous studies and were included next to mothers. Moreover, this is the first study that focused on mechanisms by which parents' and children's cognitive biases are related.

However, the findings of the current study should be placed in the light of the following limitations. First, the small sample size of the current study may have hampered to detect significant associations and moderating or mediating effects. In addition, we did not correct our statistical analyses for multiple testing because of the small sample and explorative character of the analyses. Second, although we examined parents' attention bias, we did not assess interpretation bias of parents. Third, because of the cross-sectional nature of the current study, we could not differentiate whether children's cognitive bias was amplified by parents cognitive bias or rearing style, or whether parents developed an attention bias as a response to their child's heightened anxiety. For this purpose, future longitudinal studies with larger sample sizes are needed.

If replicated in a larger sample, our findings could have clinical implications that may guide the involvement of parents in the treatment of childhood anxiety disorders. Even though parents are generally involved along the side during CBT, debate remains whether additional sessions for parents increase treatment effectiveness (Breinholst et al. 2012). As attention bias of mothers and interpretation bias of anxietydisordered children are interrelated it may be beneficial to target maternal cognitive biases to improve anxiety recovery rates. First, maternal cognitive biases could be specifically addressed during parental sessions using ABM (Hakamata et al. 2010). Second, in addition to psychoeducation regarding childhood anxiety, parents of children with anxiety disorders may be informed how cognitive biases operate within their daily rearing practices. A previous pre-post treatment study showed that teaching mothers of anxious children child management skills reduced maternal interpretation bias at post-treatment (Creswell et al. 2005). However, it should be noted that the effect we found regarding the familial aggregation of cognitive biases in our study was small. Future studies with larger sample sizes and hence more statistical power are needed to examine other factors that explain the familial aggregation of cognitive biases for anxiety disorders.

\section{Conclusion}

The results of the current clinical study add to previous community studies by demonstrating how cognitive biases between parents and children are interrelated in clinical samples. Findings indicate a possible familial aggregation across type of bias between children with anxiety disorders and their mothers. This aggregation was not dependent on maternal psychopathology, nor did we find evidence for a mediating role of maternal rearing styles. Therefore, the mechanism through which cognitive biases operate warrants further research.

Acknowledgment We gratefully acknowledge the contribution of children and parents who participated in the study. We would like to thank Esraa Marouf for her assistance with data preparation.

Funding This work was supported by the Sophia Children's Hospital Research Foundation (SSWO), Project S13-11 and the Coolsingel Foundation, Project 251.

\section{Compliance with Ethical Standards}

Conflict of Interest JM. de Lijster, E. M. W. J. Utens, G. C. Dieleman, T. M. Alexander, M. H. J. Hillegers, and J. S. Legerstee declare that they have no conflict of interest. 
Ethical Approval All procedures performed in studies involving human participants were in accordance with the ethical standards of the institutional and/or national research committee and with the 1964 Helsinki declaration and its later amendments or comparable ethical standards.

Informed Consent This study was approved by the Medical Ethics Committee of the Erasmus Medical Centre in Rotterdam (MEC-2013375). All participants provided informed consent prior to the completion of any study measures.

Animal Rights No animal studies were carried out by the authors for this article.

Open Access This article is distributed under the terms of the Creative Commons Attribution 4.0 International License (http://creativeco mmons.org/licenses/by/4.0/), which permits unrestricted use, distribution, and reproduction in any medium, provided you give appropriate credit to the original author(s) and the source, provide a link to the Creative Commons license, and indicate if changes were made.

\section{References}

Abend, R., de Voogd, L., Salemink, E., Wiers, R. W., Pérez-Edgar, K., Fitzgerald, A., et al. (2018). Association between attention bias to threat and anxiety symptoms in children and adolescents. Depression and Anxiety., 35(3), 229-238. https://doi.org/10.1002/ da.22706.

Aktar, E., van Bockstaele, B., Perez-Edgar, K., Wiers, R. W., \& Bogels, S. M. (2019). Intergenerational transmission of attentional bias and anxiety. Developmental Science, 22(3), e12772. https://doi. org/10.1111/desc. 12772 .

Andrews, G., \& Peters, L. (1998). The psychometric properties of the composite international diagnostic interview. Social Psychiatry and Psychiatric Epidemiology, 33(2), 80-88.

Biehl, M., Matsumoto, D., Ekman, P., Hearn, V., Heider, K., Kudoh, T., et al. (1997). Matsumoto and Ekman's Japanese and Caucasian Facial Expressions of Emotion (JACFEE): Reliability data and cross-national differences. Journal of Nonverbal Behavior, $21(1), 3-21$.

Blossom, J. B., Ginsburg, G. S., Birmaher, B., Walkup, J. T., Kendall, P. C., Keeton, C. P., et al. (2013). Parental and family factors as predictors of threat bias in anxious youth. Cognitive Therapy and Research, 37(4), 812-819. https://doi.org/10.1007/s1060 8-012-9513-0.

Bögels, S., \& Phares, V. (2008). Fathers' role in the etiology, prevention and treatment of child anxiety: A review and new model. Clinical Psychology Review, 28(4), 539-558. https://doi.org/10.1016/j. cpr.2007.07.011.

Breinholst, S., Esbjorn, B. H., Reinholdt-Dunne, M. L., \& Stallard, P. (2012). CBT for the treatment of child anxiety disorders: A review of why parental involvement has not enhanced outcomes. Journal of Anxiety Disorders, 26(3), 416-424. https://doi.org/10.1016/j. janxdis.2011.12.014.

Chorpita, B. F., \& Barlow, D. H. (1998). The development of anxiety: The role of control in the early environment. Psychological Bulletin, 124(1), 3-21.

Connell, A. M., \& Goodman, S. H. (2002). The association between psychopathology in fathers versus mothers and children's internalizing and externalizing behavior problems: A metaanalysis. Psychological Bulletin, 128(5), 746-773. https://doi. org/10.1037/0033-2909.128.5.746.
Cooper, L., Peters, L., \& Andrews, G. (1998). Validity of the composite international diagnostic interview (CIDI) psychosis module in a psychiatric setting. Journal of Psychiatric Research, 32(6), 361-368.

Creswell, C., O'Connor, T. G., \& Brewin, C. R. (2006). A longitudinal investigation of maternal and child 'anxious cognitions'. Cognitive Therapy and Research, 30(2), 135-147. https://doi.org/10.1007/ s10608-006-9021-1.

Creswell, C., \& O'Connor, T. G. (2006). Anxious cognitions in children: An exploration of associations and mediators. British Journal of Developmental Psychology, 24(4), 761-766. https://doi. org/10.1348/026151005X70418.

Creswell, C., Schniering, C. A., \& Rapee, R. M. (2005). Threat interpretation in anxious children and their mothers: Comparison with nonclinical children and the effects of treatment. Behaviour Research Therapy, 43(10), 1375-1381. https://doi.org/10.1016/j. brat.2004.10.009.

Creswell, C., Shildrick, S., \& Field, A. P. (2011). Interpretation of ambiguity in children: A prospective study of associations with anxiety and parental interpretations. Journal of Child and Family Studies, 20(2), 240-250. https://doi.org/10.1007/s1082 6-010-9390-7.

Darling, N., \& Steinberg, L. (1993). Parenting style as context: An integrative model. Psychological Bulletin, 113(3), 487.

de Lijster, J. M., Dieleman, G. C., Utens, E. M. W. J., van der Ende, J., Alexander, T. M., Boon, A., et al. (2019). Online attention bias modification in combination with cognitive-behavioural therapy for children and adolescents with anxiety disorders: A randomised controlled trial. Behaviour Change. https://doi.org/10.1017/ bec.2019.8.

Dodd, H. F., Hudson, J. L., Morris, T. M., \& Wise, C. K. (2012). Interpretation bias in preschool children at risk for anxiety A prospective study. Journal of Abnormal Psychology, 121(1), 28-38. https ://doi.org/10.1037/a0024589.

Dudeney, J., Sharpe, L., \& Hunt, C. (2015). Attentional bias towards threatening stimuli in children with anxiety: A meta-analysis. Clinical Psychology Review, 40, 66-75. https://doi.org/10.1016/j. cpr.2015.05.007.

Eley, T. C., Gregory, A. M., Lau, J. Y. F., McGuffin, P., Napolitano, M., Rijsdijk, F. V., et al. (2008). In the face of uncertainty: A twin study of ambiguous information, anxiety and depression in children. Journal of Abnormal Child Psychology, 36(1), 55-65. https://doi.org/10.1007/s10802-007-9159-7.

Finegood, E. D., Raver, C. C., DeJoseph, M. L., \& Blair, C. (2017). Parenting in poverty: Attention bias and anxiety interact to predict parents' perceptions of daily parenting hassles. Journal of Family Psychology, 31(1), 51-60. https://doi.org/10.1037/fam0000291.

Fisak, B., Jr., \& Grills-Taquechel, A. E. (2007). Parental modeling, reinforcement, and information transfer: Risk factors in the development of child anxiety? Clinical Child and Family Psychology Review, 10(3), 213-231. https://doi.org/10.1007/s1056 7-007-0020-x.

Gibb, B. E., Johnson, A. L., Benas, J. S., Uhrlass, D. J., Knopik, V. S., \& McGeary, J. E. (2011). Children's 5-HTTLPR genotype moderates the link between maternal criticism and attentional biases specifically for facial displays of anger. Cognition \& Emotion, 25(6), 1104-1120. https://doi.org/10.1080/02699931.2010.50826 7.

Gifford, S., Reynolds, S., Bell, S., \& Wilson, C. (2008). Threat interpretation bias in anxious children and their mothers. Cognition \& Emotion, 22(3), 497-508. https://doi.org/10.1080/0269993080 1886649.

Gulley, L. D., Oppenheimer, C. W., \& Hankin, B. L. (2014). Associations among negative parenting, attention bias to anger, and social anxiety among youth. Developmental Psychology, 50(2), 577-585. https://doi.org/10.1037/a0033624. 
Hadwin, J. A., Garner, M., \& Perez-Olivas, G. (2006). The development of information processing biases in childhood anxiety: A review and exploration of its origins in parenting. Clinical Psychology Review, 26(7), 876-894. https://doi.org/10.1016/j. cpr.2005.09.004.

Hakamata, Y., Lissek, S., Bar-Haim, Y., Britton, J. C., Fox, N. A., Leibenluft, E., et al. (2010). Attention bias modification treatment: A meta-analysis toward the establishment of novel treatment for anxiety. Biological Psychiatry, 68(11), 982-990. https ://doi.org/10.1016/j.biopsych.2010.07.021.

In-Albon, T., Dubi, K., Rapee, R. M., \& Schneider, S. (2009). Forced choice reaction time paradigm in children with separation anxiety disorder, social phobia, and nonanxious controls. Behaviour Research and Therapy, 47(12), 1058-1065. https://doi. org/10.1016/j.brat.2009.08.003.

Kilic, E. Z., Ozguven, H. D., \& Sayil, I. (2003). The psychological effects of parental mental health on children experiencing disaster: The experience of Bolu earthquake in Turkey. Family Process, 42(4), 485-495. https://doi.org/10.1111/j.1545-5300.2003.00485 .x.

Knol, F., Boelhouwer, J., \& Veldheer, V. (2012). Summary: Neighbourhood status development in the Netherlands 1998-2010. Den Haag: Sociaal en Cultureel Planbureau.

Kujawa, A. J., Torpey, D., Kim, J., Hajcak, G., Rose, S., Gotlib, I. H., et al. (2011). Attentional biases for emotional faces in young children of mothers with chronic or recurrent depression. Journal of Abnormal Child Psychology, 39(1), 125-135. https://doi. org/10.1007/s 10802-010-9438-6.

Lang, P. J., Bradley, M. M., \& Cuthbert, B. N. (1997). International affective picture system (IAPS): Technical manual and affective ratings. NIMH Center for the Study of Emotion and Attention, 1, 39-58.

Lau, J. Y. F., Hilbert, K., Goodman, R., Gregory, A. M., Pine, D. S., Viding, E. M., et al. (2012). Investigating the genetic and environmental bases of biases in threat recognition and avoidance in children with anxiety problems. Biology of Mood \& Anxiety Disorders, 2, 12. https://doi.org/10.1186/2045-5380-2-12.

Legerstee, J. S., Tulen, J. H., Kallen, V. L., Dieleman, G. C., Treffers, P. D., Verhulst, F. C., et al. (2009). Threat-related selective attention predicts treatment success in childhood anxiety disorders. Journal of the American Academy of Child \& Adolescent Psychiatry, 48(2), 196-205. https://doi.org/10.1097/CHI.0b013e31819176e4.

Legerstee, J. S., \& Utens, E. M. W. J. (2018). Pioneering research into specificity of intergenerational transmission of interpretation biases from parents to children: Challenges for the future. Journal of the American Academy of Child \& Adolescent Psychiatry, 57(7), 454-456. https://doi.org/10.1016/j.jaac.2018.02.018.

Lester, K. J., Field, A. P., Oliver, S., \& Cartwright-Hatton, S. (2009). Do anxious parents interpretive biases towards threat extend into their child's environment? Behaviour Research and Therapy, 47(2), 170-174. https://doi.org/10.1016/j.brat.2008.11.005.

Lonigan, C. J., Vasey, M. W., Phillips, B. M., \& Hazen, R. A. (2004). Temperament, anxiety, and the processing of threat-relevant stimuli. Journal of Clinical Child \& Adolescent Psychology, 33(1), 8-20. https://doi.org/10.1207/S15374424JCCP3301_2.

Low, N. C. P., Dugas, E., Constantin, E., Karp, I., Rodriguez, D., \& O'Loughlin, J. (2012). The association between parental history of diagnosed mood/anxiety disorders and psychiatric symptoms and disorders in young adult offspring. BMC Psychiatry, 12(1), 188. https://doi.org/10.1186/1471-244X-12-188.

Markus, M. T., Lindhout, I. E., Boer, F., Hoogendijk, T. H. G., \& Arrindell, W. A. (2003). Factors of perceived parental rearing styles: The EMBU-C examined in a sample of Dutch primary school children. Personality and Individual Differences, 34(3), 503-519. https://doi.org/10.1016/S0191-8869(02)00090-9.
Matsumoto, D., \& Ekman, P. (1988). Japanese and Caucasian Facial Expressions of Emotion (JACFEE). San Francisco, CA: Intercultural and Emotion Research Laboratory, Department of Psychology, San Francisco State University.

McHugh, M. L. (2012). Interrater reliability: The kappa statistic. Biochemia Medica, 22(3), 276-282. https://doi.org/10.11613/ BM.2012.031.

Mogg, K., Waters, A. M., \& Bradley, B. P. (2017). Attention bias modification (ABM): Review of effects of multisession ABM training on anxiety and threat-related attention in high-anxious individuals. Clinical Psychological Science, 5(4), 698-717. https://doi.org/10.1177/2167702617696359.

Montagner, R., Mogg, K., Bradley, B. P., Pine, D. S., Czykiel, M. S., Miguel, E. C., et al. (2016). Attentional bias to threat in children at-risk for emotional disorders: Role of gender and type of maternal emotional disorder. European Child \& Adolescent Psychiatry, 25(7), 735-742. https://doi.org/10.1007/s0078 7-015-0792-3.

Moors, A., De Houwer, J., Hermans, D., Wanmaker, S., van Schie, K., Van Harmelen, A. L., et al. (2013). Norms of valence, arousal, dominance, and age of acquisition for 4300 Dutch words. Behaviour Research Methods, 45(1), 169-177. https://doi.org/10.3758/ s13428-012-0243-8.

Muris, P., Kindt, M., Bögels, S., Merckelbach, H., Gadet, B., \& Moulaert, V. (2000). Anxiety and threat perception abnormalities in normal children. Journal of Psychopathology and Behavioral Assessment, 22(2), 183-199. https://doi.org/10.1023/A:10075 88524525.

Muris, P., van Zwol, L., Huijding, J., \& Mayer, B. (2010). Mom told me scary things about this animal: Parents installing fear beliefs in their children via the verbal information pathway. Behaviour Research Therapy, 48(4), 341-346. https://doi.org/10.1016/j. brat.2009.12.001.

Ooi, J., Dodd, H. F., Fliek, L., \& Muris, P. (2016). The development of anxiety in childhood and adolescence: The transmission of cognitive biases. In R. G. Menzies, M. Kyrios, \& N. Kazantzis (Eds.), Innovations and future directions in the behavioural and cognitive therapies. Samford Valley: Australian Academic Press.

Pérez-Edgar, K., Reeb-Sutherland, B. C., McDermott, J. M., White, L. K., Henderson, H. A., Degnan, K. A., et al. (2011). Attention biases to threat link behavioral inhibition to social withdrawal over time in very young children. Journal of Abnormal Child Psychology, 39(6), 885-895. https://doi.org/10.1007/s10802-011-9495-5.

Pine, D. S., Helfinstein, S. M., Bar-Haim, Y., Nelson, E., \& Fox, N. A. (2009). Challenges in developing novel treatments for childhood disorders: Lessons from research on anxiety. Neuropsychopharmacology, 34(1), 213-228. https://doi.org/10.1038/npp.2008.113.

Preacher, K. J., \& Hayes, A. F. (2008). Asymptotic and resampling strategies for assessing and comparing indirect effects in multiple mediator models. Behaviour Research Methods, 40(3), 879-891. https://doi.org/10.3758/BRM.40.3.87.

Puliafico, A. C., \& Kendall, P. C. (2006). Threat-related attentional bias in anxious youth: A review. Clinical Child and Family Psychology Review, 9(3-4), 162-180. https://doi.org/10.1007/s1056 7-006-0009-x.

Remmerswaal, D., Muris, P., \& Huijding, J. (2016). Transmission of cognitive bias and fear from parents to children: An experimental study. Journal of Clinical Child \& Adolescent Psychology, 45(5), 642-654. https://doi.org/10.1080/15374416.2014.987378.

Roy, A. K., Vasa, R. A., Bruck, M., Mogg, K., Bradley, B. P., Sweeney, M., et al. (2008). Attention bias toward threat in pediatric anxiety disorders. Journal of the American Academy of Child and Adolescent Psychiatry, 47(10), 1189-1196. https://doi.org/10.1097/ CHI.0b013e3181825ace.

Shechner, T., Rimon-Chakir, A., Britton, J. C., Lotan, D., Apter, A., \& Bar-Haim, Y. (2014). Attention bias modification treatment 
augmenting effects on cognitive behavioral therapy in children with anxiety: Randomized controlled trial. Journal of the American Academy of Child and Adolescent Psychiatry, 53(1), 61-71. https://doi.org/10.1016/j.jaac.2013.09.016.

Waters, A. M., Candy, E. M., \& Candy, S. G. (2018). Attention bias to threat in mothers with emotional disorders predicts increased offspring anxiety symptoms: A joint cross-sectional and longitudinal analysis. Cognition \& Emotion. https://doi.org/10.1080/02699 931.2017.1349650.

Waters, A. M., \& Craske, M. G. (2016). Towards a cognitive-learning formulation of youth anxiety: A narrative review of theory and evidence and implications for treatment. Clinical Psychology Review, 50, 50-66. https://doi.org/10.1016/j.cpr.2016.09.008.

Waters, A. M., Forrest, K., Peters, R. M., Bradley, B. P., \& Mogg, K. (2015). Attention bias to emotional information in children as a function of maternal emotional disorders and maternal attention biases. Journal of Behaviour Therapy and Experimental Psychiatry, 46, 158-163. https://doi.org/10.1016/j.jbtep.2014.10.002.

Waters, A. M., Henry, J., Mogg, K., Bradley, B. P., \& Pine, D. S. (2010). Attentional bias towards angry faces in childhood anxiety disorders. Journal of Behaviour Therapy and Experimental Psychiatry, 41(2), 158-164. https://doi.org/10.1016/j.jbtep .2009.12.001.
Waters, A. M., Mogg, K., \& Bradley, B. P. (2012). Direction of threat attention bias predicts treatment outcome in anxious children receiving cognitive-behavioural therapy. Behaviour Research Therapy, 50(6), 428-434. https://doi.org/10.1016/j. brat.2012.03.006.

WHO. (1997). Composite international diagnostic interview (CIDI), version 21. Geneva: World Health Organization.

Wittchen, H. U. (1994). Reliability and validity studies of the WHOcomposite international diagnostic interview (CIDI): A critical review. Journal of Psychiatric Research, 28(1), 57-84.

Wittchen, H. U., Lecrubier, Y., Beesdo, K., \& Nocon, A. (2007). Relationships among anxiety disorders: Patterns and implications. In D. Nutt \& J. Ballenger (Eds.), Anxiety disorders (pp. 23-37). New Jersey: Blackwell Science Ltd.

Publisher's Note Springer Nature remains neutral with regard to jurisdictional claims in published maps and institutional affiliations. 